\title{
Reply to Comment on "Aysheaia prolata from the Utah Wheeler Formation (Drumian, Cambrian) is a frontal appendage of the radiodontan Stanleycaris" with the formal description of Stanleycaris
}

\author{
Stephen Pates, Allison C. Daley, and Javier Ortega-Hernández \\ Acta Palaeontologica Polonica 63 (1), 2018: 105-110 doi:http://dx.doi.org/10.4202/app.00443.2017
}

As part of a comprehensive examination of all radiodontans from Cambrian localities in the USA, Pates et al. (2017a, b) and Pates and Daley (2017) revised the taxonomic affinities of several described specimens. This included the reinterpretation of two putative lobopodians, one from the Wheeler Formation (Utah, USA) and one from the Valdemiedes Formation (Spain), as frontal appendages of the radiodontan genera Stanleycaris and Caryosyntrips respectively. In their comment, Gámez Vintaned and Zhuravlev (2018) disagree with these conclusions and raise three topics for discussion: (i) anatomical features they suggest support a lobopodian affinity for "Mureropodia"; (ii) the identity of Caryosyntrips as a radiodontan, and the assignment of certain specimens to this genus; and (iii) the nomenclatural status of Stanleycaris hirpex as an invalid taxon. For (i), we dispute that the anatomical features put forward by Gámez Vintaned and Zhuravlev (2018) are biological and conclude that a lobopodian affinity for Mureropodia is untenable. In response to (ii), we provide further evidence supporting a radiodontan affinity for Caryosyntrips , and those specimens ascribed to this genus. Finally, we concur with (iii) Stanleycaris as an invalid taxon according to the International Code on Zoological Nomenclature (ICZN), and have rectified the situation by providing a valid systematic description.

Stephen Pates [stephen.pates@ zoo.ox.ac.uk], Department of Zoology, University of Oxford, Oxford, OX1 3PS, UK. Allison C. Daley [allison.daley@ unil.ch], Institute of Earth Sciences, University of Lausanne, Géopolis, CH-1015, Lausanne, Switzerland. Javier Ortega-Hernández [jo314@cam.ac.uk], Department of Zoology, Downing Street, University of Cambridge, Cambridge, CB2 3EJ, UK. 
Attribution License (for details please see creativecommons.org), which permits unrestricted use, distribution, and reproduction in any medium, provided the original author and source are credited.

FaF Full text $(556.2 \mathrm{kB})$ 